\title{
Gas turbine unite inlet air cooling by using an excessive refrigeration capacity of absorption-ejector chiller in booster air cooler
}

\author{
Roman Radchenko ${ }^{1}$, Andrii Radchenko, ${ }^{1, *}$, Serhiy Serbin ${ }^{1}$, Serhiy Kantor ${ }^{1}$, and Bohdan Portnoi ${ }^{1}$ \\ ${ }^{1}$ Admiral Makarov National University of Shipbuilding, pr. Heroes of Ukraine, 9, Mykolaiv, Ukraine
}

\begin{abstract}
Two-stage Gas turbine unite (GTU) inlet air cooling by absorption lithium-bromide chiller (ACh) to the temperature $15{ }^{\circ} \mathrm{C}$ and by refrigerant ejector chiller $(\mathrm{ECh})$ to $10{ }^{\circ} \mathrm{C}$ through utilizing the turbine exhaust gas heat for changeable ambient air temperatures and corresponding heat loads on the air coolers for the south Ukraine climatic conditions is analysed. An excessive refrigeration capacity of combined absorption-ejector chiller (AECh) exceeding the current heat loads and generated at decreased heat loads on the air coolers at the inlet of GTU can be used for covering increased heat loads to reduce the refrigeration capacity of AECh. The GTU inlet air cooling system with an ambient air precooling booster stage and a base two-stage cooling air to the temperature $10^{\circ} \mathrm{C}$ by $\mathrm{AECh}$ is proposed. The AECh excessive cooling capacity generated during decreased heat loads on the GTU inlet air coolers is conserved in the thermal accumulator and used for GTU inlet air precooling in a booster stage of air cooler during increased heat loads. There is AECh cooling capacity reduction by $50 \%$ due to the use of a booster stage for precooling GTU inlet ambient air at the expense of an excessive cooling capacity accumulated in the thermal storage.
\end{abstract}

\section{Introduction}

Gas turbine unit (GTU) inlet air cooling by waste heat recovery refrigeration machine (HRRM) which transforms the exhaust gas heat into the cold is one of the main trends in increasing GTU efficiency. Gas turbine inlet air can be cooled to the temperature $\mathrm{t}_{a 2} \approx$ $15^{\circ} \mathrm{C}$ by transformation of waste heat into the cold with a high efficiency in the most widespread absorption lithium-bromide chiller (ACh). Its coefficient of performance is $\zeta=0.7 \ldots 0.8[1,2]$. Deeper air cooling to the temperature $\mathrm{t}_{a 2}=10^{\circ} \mathrm{C}$ and below is possible in refrigerant ejector chiller (ECh). The efficiency of transformation of waste heat into the cold by ECh is much less: $\zeta=0.2 \ldots 0.3$ [3]. Therefore it is rational to use two-stage air cooling at the GTU inlet: to $\mathrm{t}_{a 2}=15 \ldots 20^{\circ} \mathrm{C}$ in the ACh and to $\mathrm{t}_{a 2}=7 \ldots 10^{\circ} \mathrm{C}$ in the $\mathrm{ECh}$, that is in the combined absorption-ejector chiller (AECh) $[4,5]$. The heat load on the air cooler (AC) at the GTU inlet changes significantly according to the current ambient air temperature $\mathrm{t}_{a m b}$ and relative humidity $\varphi_{\mathrm{amb}}$ that leads to adequate change of AECh cooling capacity. A cooling capacity reserve (AECh installed excessive heat load value compared with current heat loads) is conserved during reduced heat loads. It is expedient to cover the deficit of cooling capacity at high loads, thereby reducing the $\mathrm{ACh}$ installed cooling capacity and it cost.

Objective: reduction of the installed absorption chiller cooling capacity by conserving an excessive cooling capacity at low current heat loads on the air cooler at the inlet of GTU and using the reserved cooling capacity for ambient air precooling at increased current heat loads.

\section{Results of investigation}

The GTU inlet air cooling efficiency can be conveniently estimated by the annual temperature-hour potential, $\prod_{\Sigma},{ }^{\circ} \mathrm{C} \cdot \mathrm{h}$, which represents the air temperature drop $\Delta t_{a}$ at the GTU inlet and the duration $\tau$ of GTU operation at reduced temperatures [4]

$$
\Pi_{\Sigma}=\sum\left(\Delta t_{a} \cdot \tau\right) .
$$

To determine the specific cooling capacity of twostage AECh as the total cooling capacity related to the unit of air flow $\left(G_{a}=1 \mathrm{~kg} / \mathrm{s}\right)$

$$
q_{0}=Q_{0} / G_{a}
$$

it is necessary to analyze the annual temperature-hour potential $\prod_{\Sigma}{ }^{\circ}$ dependence on specific cooling capacity $q_{0}$. The specific cooling capacity is calculated as

$$
q_{0}=\xi \cdot c_{m a} \cdot\left(t_{a m b}-t_{a 2}\right), \mathrm{kW} /(\mathrm{kg} / \mathrm{s}), \text { or } \mathrm{kJ} / \mathrm{kg},
$$

where $\xi$ is the moisture coefficient; $t_{a m b}$ - ambient air temperature, ${ }^{\circ} \mathrm{C} ; t_{a 2}$ - air temperature at the air cooler outlet, ${ }^{\circ} \mathrm{C} ; c_{m a}-$ moist air specific heat, $\mathrm{kJ} /(\mathrm{kg} \cdot \mathrm{K})$.

Corresponding author: nirad50@gmail.com 
The project (installed) specific cooling capacity $q_{0}$, on the one hand, should cover the GTU inlet air cooling need for as long time as possible during the year, which would have the greatest effect in the fuel saving. On the other hand, it should not be overestimated so that for most of the year the AECh was operated at thermal loads close to the project value, otherwise there would be an AECh operation at partial loads far from the project value. And on the contrary, with the lowered project $q_{0}$ there will be undercooling of the GTU inlet air at high ambient temperatures $t_{\text {amb }}$.

Fig. 1 shows the value of annual specific fuel saving $b_{e}$ depending on the specific cooling capacity values $q_{0}$ (with $G_{a}=1 \mathrm{~kg} / \mathrm{s}$ ) for ambient air cooled to the temperatures $t_{a 2}=15^{\circ} \mathrm{C}$ in $\mathrm{ACh}$ and to $t_{a 2}=10^{\circ} \mathrm{C}$ in two-stage AECh for 2017 year, Yuzhnoukrainsk city, Mykolaiv region, Ukraine.

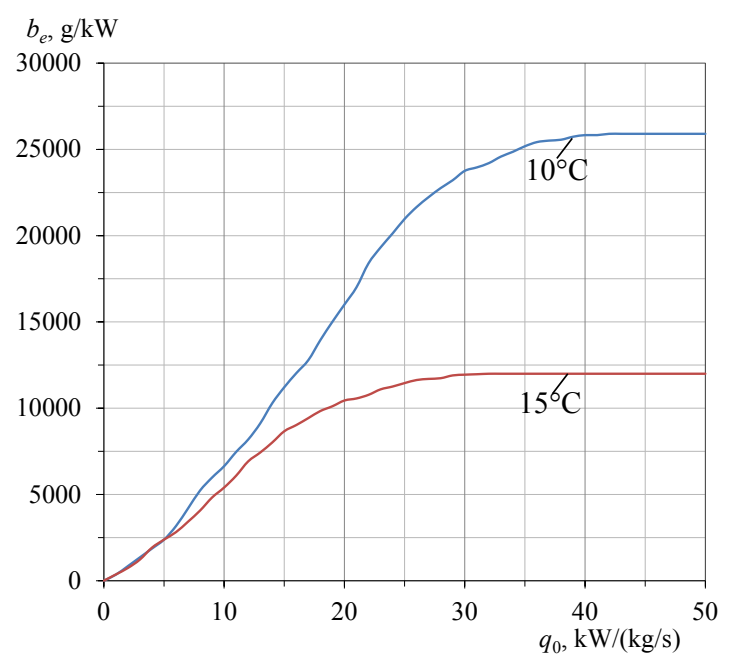

Fig. 1. The value of annual specific fuel saving $b_{e}$ depending on the specific cooling capacity values $q_{0}$ (with $G_{a}=1 \mathrm{~kg} / \mathrm{s}$ ) for cooling an ambient air to the temperatures $t_{a 2}=10^{\circ} \mathrm{C}$ in AECh and to $15^{\circ} \mathrm{C}$ in Ach.

As can be seen from Fig. 1, for the climatic conditions of the GTU operation in the Yuzhnoukrainsk city, Mykolaiv region, 2017, a specific cooling capacity $q_{0}=34 \mathrm{~kW} /\left(\mathrm{kg} / \mathrm{s}\right.$ ) (for $G_{a}=1 \mathrm{~kg} / \mathrm{s}$ ) can be considered as rational project $\mathrm{AECh}$ specific cooling capacity for cooling ambient air at the inlet of GTU to the temperature $t_{a 2}=10{ }^{\circ} \mathrm{C}$ at which the annual specific fuel saving $b_{e}$ is kept closed to the maximum value at high enough rate of its increment. When air is cooled to $t_{a 2}{ }^{\circ}=15^{\circ} \mathrm{C}$ in $\mathrm{ACh}$ the rational project $\mathrm{AECh}$ specific cooling capacity is respectively $q_{0}=24 \mathrm{~kW} /(\mathrm{kg} / \mathrm{s})$. Proceeding from the rational specific cooling capacity $q_{0}$ the total installed cooling capacity of AECh in accordance with the air flow $G_{a}$ through the GTU is chosen as

$$
Q_{0}=G_{a} \cdot q_{0}, \mathrm{~kW} .
$$

Since a decrease in the rate of the annual specific fuel saving increment $b_{e}$ at high cooling capacity indicates that there is an excess of cold, it is advisable to determine the cooling capacity, which ensures its maximum build-up rate, which will be less than $q_{0}=24 \mathrm{~kW} /(\mathrm{kg} / \mathrm{s})$ for $t_{a 2}=15^{\circ} \mathrm{C}$ for $\mathrm{ACh}$, as shown in Fig. 1.

To determine the cooling capacity, which provides a maximum build-up rate, it is necessary to analyze the annual specific fuel saving $b_{e}$ related to the specific cooling capacity $q_{0}, b_{e} / q_{0}$, in dependence on the specific cooling capacity values $q_{0}$ (Fig. 2) for the cooled air temperatures $t_{a 2}=10$ and $15^{\circ} \mathrm{C}$.

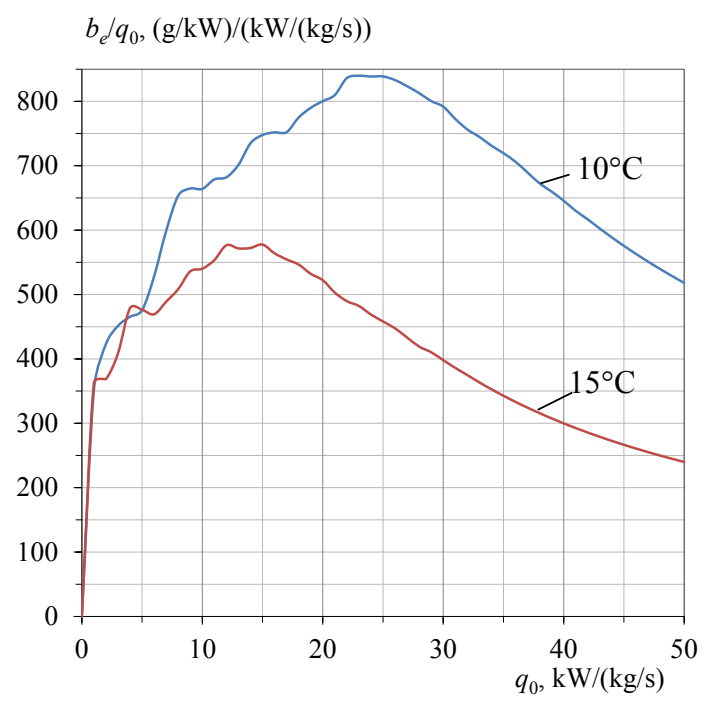

Fig. 2. The values of annual specific fuel saving related to the specific cooling capacity $b_{e} / q_{0}$ in dependence on the project specific cooling capacity $q_{0}$ for the cooled air temperature $t_{a 2}=10$ and $15^{\circ} \mathrm{C}$.

As can be seen from Fig. 2, for the climatic conditions of the GTU operation, the maximum rate of increment in the annual specific fuel saving $b_{e} / q_{0}$ due to cooling (maximum of the graph) for the temperature of air $t_{a 2}=15^{\circ} \mathrm{C}$ cooled in the $\mathrm{ACh}$ takes place at the project specific cooling capacity values $q_{0}=$ $=12 \ldots 16 \mathrm{~kW} /(\mathrm{kg} / \mathrm{s})$, and when air is cooled to $t_{a 2}=10^{\circ} \mathrm{C}$ in two-stage AECh $q_{0}{ }^{\circ}={ }^{\circ} 22 \ldots 26^{\circ} \mathrm{kW} /(\mathrm{kg} / \mathrm{s})$. The corresponding total project (installed) cooling capacities,

$$
Q_{0}=G_{a} \cdot q_{0}, \mathrm{~kW} \text {. }
$$

provide the maximum rate of the annual specific fuel saving increment.

Since the project (installed) specific cooling capacity values $q_{0}$, which ensure the maximum rate of increment in the annual specific fuel saving $b_{e} / q_{0}$ (Fig. 2) are less than their values determined in accordance with the maximum annual specific fuel saving $b_{e}$ in Fig. 1, then at an increased ambient air temperature $t_{a m b}$ there will be a deficit of cooling capacity, while at low ambient air temperatures $t_{a m b}$, on the contrary, its excess. The excess of cooling capacity, generated during reduced heat load periods, is expedient to accumulate in the cold storage and use during increased heat loads in the pre-cooling air booster stage $\mathrm{AC}_{\mathrm{B}}$ of air cooler.

With this the reserve of ACh cooling capacity, generated during current reduced heat loads, is defined as its excess compared with the current heat load on the basic high-temperature stage $\mathrm{AC}_{\mathrm{HT}}$ and the pre-cooling air booster stage $\mathrm{AC}_{\mathrm{B}}$, that is, on the heat exchanger 
"AC $\mathrm{HT}_{\mathrm{HT}}+\mathrm{AC}_{\mathrm{B}}$ ". The ECh cooling capacity reserve is also defined as the project $\mathrm{ECh}$ heat load excess over the current heat loads on the low-temperature stage $\mathrm{AC}_{\mathrm{LT}}$ of air cooler and the total cooling capacity reserve of AECh is the sum of $\mathrm{ACh}$ and $\mathrm{ECh}$ reserves.

The total project heat load on the $\mathrm{AC}_{\mathrm{HT}}$ is defined as

$$
Q_{0 . H T 16 p r}=q_{0 \cdot H T 16 p r} \cdot G_{a}=16 \cdot 40=640 \mathrm{~kW}
$$

and is based on the $\mathrm{AC}_{\mathrm{HT}}$ project specific heat load $q_{0 \cdot H T 16 p r}=16 \mathrm{~kW} /(\mathrm{kg} / \mathrm{s})$. With this the project heat load on the $\mathrm{AC}_{\mathrm{HT}}$ with pre-cooling air booster stage $\mathrm{AC}_{\mathrm{B}}$ :

$$
Q_{0 . H T 24 p r}=q_{0 . H T 24 p r} \cdot G_{a}=24 \cdot 40=960 \mathrm{~kW},
$$

where $q_{0 . H T 24 p r}=24 \mathrm{~kW} /(\mathrm{kg} / \mathrm{s})$ - the total specific heat load on both $\mathrm{AC}_{\mathrm{HT}}$ and $\mathrm{AC}_{\mathrm{B}}$, that provides the maximum annual fuel saving due to GTU inlet air cooling to the temperature $t_{H T 2} \approx 15^{\circ} \mathrm{C}$ in ACh according to Fig. 1 [3]. The air consumption is $G_{a}=40 \mathrm{~kg} / \mathrm{s}$. The project heat load on the $\mathrm{AC}_{\mathrm{LT}}$ is defined as

$$
Q_{0 . L T 10 p r}=q_{0 . L T 10 p r} \cdot G_{a}=10 \cdot 40=400 \mathrm{~kW},
$$

and based on the project specific heat load on the $\mathrm{AC}_{\mathrm{LT}}$ $q_{0 . L T 10 p r}=10 \mathrm{~kW} /(\mathrm{kg} / \mathrm{s})$ according to the maximum annual effect (Fig. 1).

In determining the $\mathrm{ACh}$ cooling capacity reserve, the current heat load on the $\mathrm{AC}_{\mathrm{HT}}$ with booster $\mathrm{AC}_{\mathrm{B}}$ is compared with the project heat load

$$
Q_{0 . H T 24 p r}=24 \cdot 40=960 \mathrm{~kW},
$$

where $q_{0 . H T 24 p r}=24 \mathrm{~kW}(\mathrm{~kg} / \mathrm{s})$.

Partial replacement of high-temperature stage $\mathrm{AC}_{\mathrm{HT}}$ by pre-cooling air booster stage $\mathrm{AC}_{\mathrm{B}}$ with corresponding reduction of the project cooling capacity of $\mathrm{ACh}$ is possible if there is a reserve of the ACh cooling capacity, accumulated in the cold storage, which exceeds its spending for the ambient air precooling in the $\mathrm{AC}_{\mathrm{B}}$. In accordance with this, the $\mathrm{ACh}$ excessive cooling capacity (reserve) is defined as

$$
Q_{0 . H T 16 e x c}=Q_{0 . H T 16 p r}-Q_{0 . H T 24}=640-Q_{0 . H T 24}, \mathrm{~kW},
$$

and its deficit is respectively:

$$
Q_{0 . H T 16 \mathrm{def}}=Q_{0 . H T 24}-Q_{0 . H T 16 \mathrm{pr}}=Q_{0 . H T 24}-640, \mathrm{~kW} .
$$

The ECh excessive cooling capacity (its reserve):

$$
Q_{0 . L T 10 e x c}=Q_{0 . L T 10 p r}-Q_{0 . L T 10}=400-Q_{0 . L T 10}, \mathrm{~kW},
$$

and its deficit:

$$
Q_{0 . L T 10 d e f}=Q_{0 . L T 10}-Q_{0 . L T 10 p r}=Q_{0 . L T 10}-400, \mathrm{~kW} .
$$

The total excessive cooling capacity (total reserve) is

$$
Q_{0 . A \operatorname{Cexc}}=Q_{0 . H T 16 e x c}+Q_{0 . L T 10 e x c}, \mathrm{~kW},
$$

and the total deficit:

$$
Q_{0 . A C d e f}=Q_{0 . H T 16 \text { def }}+Q_{0 . L T 10 d e f}, \mathrm{~kW} .
$$

These balances coincide for properly selected the sum of project heat load on the basic high-temperature stage $\mathrm{AC}_{\mathrm{HT}}$ and the booster stage $\mathrm{AC}_{\mathrm{B}}$ for precooling air at the expense of the $\mathrm{ACh}$ cooling capacity reserve, as well as on the low-temperature stage $\mathrm{AC}_{\mathrm{LT}}$ at the expense of the ECh cooling capacity reserve. Of course, the cooling capacity reserve depends on the climatic conditions. The same can be said about its rational choice, taking into account the excess (reserve) of cooling capacity accumulated during a certain period. The convergence of cooling capacity excess with its deficit proves rational choice of project (installed) cooling capacity.

An example of implementing the approach to determine the booster stage $\mathrm{AC}_{\mathrm{B}}$ project heat load and a value of fuel saving due to pre-cooling air in the booster stage $\mathrm{AC}_{\mathrm{B}}$ with decreased basic high-temperature stage ACh project (installed) cooling capacity during 3 days (10-12.07.2017) is shown in Fig. 3.

As can be seen from Fig. 3, with the project heat loads $320 \mathrm{~kW}$ for pre-cooling air booster stage $\mathrm{AC}_{\mathrm{B}}$, $640 \mathrm{~kW}$ for high-temperature stage $\mathrm{AC}_{\mathrm{HT}}$ and $400 \mathrm{~kW}$ for low-temperature stage $\mathrm{AC}_{\mathrm{LT}}$, the spending of excessive cooling capacity accumulated over 3 days eliminates the ACh cooling capacity deficit, as it is proved by the change in the summarized total value of cooling capacity deficit: from $\Sigma Q_{0 . A C d e f}=2500 \mathrm{~kW} \cdot \mathrm{h}$ to $\Sigma Q_{0 . \text { ACAcdef }}=0$. The presence of cooling capacity significant excess after covering the deficit $\Sigma Q_{0 . A C A c e x c}$ confirms the correct approach to choose a reduced project heat load for the basic high-temperature stage $\mathrm{AC}_{\mathrm{HT}}$, and respectively the total heat load $1040 \mathrm{~kW}$ on the high-temperature stage $\mathrm{AC}_{\mathrm{HT}}$ and low-temperature stage $\mathrm{AC}_{\mathrm{LT}}$ (cooling capacity of $\mathrm{ACh}$ and $\mathrm{ECh}$ ) with the use of a cooling capacity reserve for the booster stage $\mathrm{AC}_{\mathrm{B}}$ in comparison with the initial project cooling capacity $1360 \mathrm{~kW}$ of $\mathrm{ACh}$ and $\mathrm{ECh}$ (without use of the booster stage $\mathrm{AC}_{\mathrm{B}}$ ), as well as the availability of a cooling capacity reserve for further reduction of the project ACh cooling capacity.

In order to increase the efficiency of using the cooling capacity reserve, an option with a larger reduction of the project load on the high-temperature stage $\mathrm{AC}_{\mathrm{HT}}$ to $480 \mathrm{~kW}$ is calculated, which is half as much as the output of $960 \mathrm{~kW}$, with an increase in the load on the pre-cooling air booster stage $\mathrm{AC}_{\mathrm{B}}$ to $480 \mathrm{~kW}$ while maintaining its value on the low-temperature stage $\mathrm{AC}_{\mathrm{LT}}$ (respectively on the ECh) $400 \mathrm{~kW}$.

As can be seen from Fig. 3, with the project heat loads $320 \mathrm{~kW}$ for pre-cooling air booster stage $\mathrm{AC}_{\mathrm{B}}$, $640 \mathrm{~kW}$ for high-temperature stage $\mathrm{AC}_{\mathrm{HT}}$ and $400 \mathrm{~kW}$ for low-temperature stage $\mathrm{AC}_{\mathrm{LT}}$, the spending of excessive cooling capacity accumulated over 3 days eliminates the ACh cooling capacity deficit, as it is proved by the change in the summarized total value of cooling capacity deficit: from $\Sigma Q_{0 . A C d e f}=2500 \mathrm{~kW} \cdot \mathrm{h}$ to $\Sigma Q_{0 . \text { ACAcdef }}=0$. The presence of cooling capacity significant excess after covering the deficit $\Sigma Q_{0 . A C A c e x c}$ confirms the correct approach to choose a reduced project heat load for the basic high-temperature stage $\mathrm{AC}_{\mathrm{HT}}$, and respectively the total heat load $1040 \mathrm{~kW}$ on the high-temperature stage $\mathrm{AC}_{\mathrm{HT}}$ and low-temperature stage $\mathrm{AC}_{\mathrm{LT}}$ (cooling capacity of $\mathrm{ACh}$ and $\mathrm{ECh}$ ) with the 


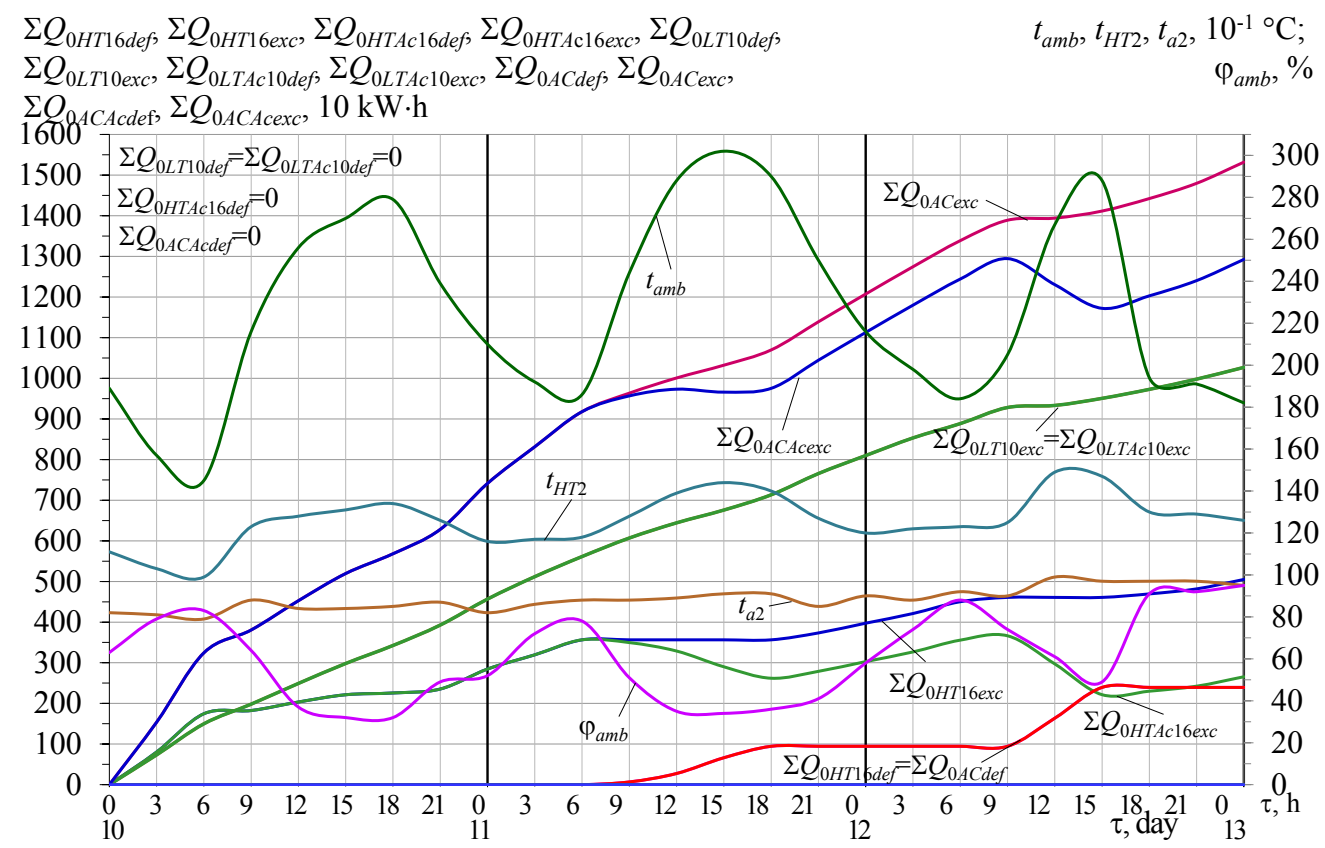

Fig. 3. The current values of the ambient air temperature $t_{a m b}$, the temperature after $\mathrm{AC}_{\mathrm{HT}} t_{H T 2}$, after $\mathrm{AC}_{\mathrm{LT}} t_{a 2}$, relative humidity of the ambient air at the inlet $\varphi_{a m b}$, the total deficit $\Sigma Q_{0 H T 16 \text { def }}$ and the excess $\Sigma Q_{0 H T 16 \text { exc }}$ of the ACh cooling capacity (without using the cooling capacity reserve in the booster stage $\mathrm{AC}_{\mathrm{B}}$ of air cooler), the total deficit $\Sigma Q_{0 \text { HTAc16def }}$ and the excess $\Sigma Q_{0 H T A c 16 e x c}$ of the cooling capacity of the $\mathrm{ACh}$ (with using the cooling capacity reserve in the booster stage $\mathrm{AC}_{\mathrm{B}}$ ), the total deficit $\Sigma Q_{0 L T 10 d e f}$ and the excess $\Sigma Q_{0 L T 10 e x c}$ of the cooling capacity of the $\mathrm{ECh}$ (without using the cooling capacity reserve in the booster stage $\mathrm{AC}_{\mathrm{B}}$ ), a total deficit $\Sigma Q_{0 L T A C 10 \text { def }}$ and the excess $\Sigma Q_{0 L T A C 10 \text { exc }}$ of the cooling capacity of the ECh (with using the cooling capacity reserve in the booster stage $\mathrm{AC}_{\mathrm{B}}$ ), the total deficit $\Sigma Q_{0 A C d e}$, and the excess $\Sigma Q_{0 A C e x c}$ of the cooling capacity of two-stage air cooler (without using the cooling capacity reserve in the booster stage $\mathrm{AC}_{\mathrm{B}}$ ), and the total deficit $\Sigma Q_{0 A C A c d e f}$, and the excess $\Sigma Q_{0 A C A c e x c}$ of the proposed air cooler cooling capacity (with using the cooling capacity reserve in the booster stage $\mathrm{AC}_{\mathrm{B}}$ ) within 3 days $(10-12.07 .2017)$.

use of a cooling capacity reserve for the booster stage $\mathrm{AC}_{\mathrm{B}}$ in comparison with the initial project cooling capacity $1360 \mathrm{~kW}$ of $\mathrm{ACh}$ and $\mathrm{ECh}$ (without use of the booster stage $\mathrm{AC}_{\mathrm{B}}$ ), as well as the availability of a cooling capacity reserve for further reduction of the project ACh cooling capacity.

In order to increase the efficiency of using the cooling capacity reserve, an option with a larger reduction of the project load on the high-temperature stage $\mathrm{AC}_{\mathrm{HT}}$ to $480 \mathrm{~kW}$ is calculated, which is half as much as the output of $960 \mathrm{~kW}$, with an increase in the load on the pre-cooling air booster stage $\mathrm{AC}_{\mathrm{B}}$ to $480 \mathrm{~kW}$ while maintaining its value on the low-temperature stage $\mathrm{AC}_{\mathrm{LT}}$ (respectively on the $\left.\mathrm{ECh}\right) 400 \mathrm{~kW}$.

The results of air cooling with project loads $480 \mathrm{~kW}$ for booster stage $\mathrm{AC}_{\mathrm{B}}, 480 \mathrm{~kW}$ for high-temperature stage $\mathrm{AC}_{\mathrm{HT}}$ and $400 \mathrm{~kW}$ for low-temperature stage $\mathrm{AC}_{\mathrm{LT}}$ $400 \mathrm{~kW}$ with using excessive cooling capacity accumulated at low heat loads for pre-cooling air in the booster stage $\mathrm{AC}_{\mathrm{B}}$ in the times of increased heat loads are presented in Fig. 4.

As can be seen from Fig. 4, with the project heat load $480 \mathrm{~kW}$ on the booster stage $\mathrm{AC}_{\mathrm{B}}, 480 \mathrm{~kW}$ for hightemperature stage $\mathrm{AC}_{\mathrm{HT}}$ and $400 \mathrm{~kW}$ for lowtemperature stage $\mathrm{AC}_{\mathrm{LT}}$, the spending of cooling capacity reserve, accumulated over 3 days, eliminates the ACh cooling capacity deficit, as evidenced by a change in its value: from $\Sigma Q_{0 . A C d e f}=9500 \mathrm{~kW} \cdot \mathrm{h}$ to $\Sigma Q_{0 . A C d e f}=0$. Accordingly, there is a reduction in the cooling capacity reserve after eliminating the deficit
$\Sigma Q_{0 . A C A c e x c}$ to about $15 \%$ of the initial version without the use of booster stage $\mathrm{AC}_{\mathrm{B}}$, which confirms the possibility of reducing the half of the initial ACh project cooling capacity through the accumulation of excessive cooling capacity during reduced heat loads on the hightemperature stage $\mathrm{AC}_{\mathrm{HT}}$ with its subsequent use for booster stage $\mathrm{AC}_{\mathrm{B}}$ at high heat loads with practically the constant heat load on the low-temperature stage $\mathrm{AC}_{\mathrm{LT}}$ and the reduced total cooling capacity $880 \mathrm{~kW}$ of the $\mathrm{ACh}$ and ECh compared to the initial value $1360 \mathrm{~kW}$ (without the using the booster stage $\mathrm{AC}_{\mathrm{B}}$ of air cooler at the GTU inlet).

Fig. 5 shows the current $B_{e}$ and the total $\Sigma B_{e}$ fuel saving calculation results depending on the climatic conditions during 3 days for such a combined ambient air cooling at the inlet of GTU.

As can be seen from Fig. 5, the high-temperature stage $\mathrm{AC}_{\mathrm{HT}}$ provides a significantly higher amount of saved fuel, compared with the low-temperature stage $\mathrm{AC}_{\mathrm{LT}}$ that proves the correct choice of decreased project heat loads of the ACh. So, the results of simulation have shown that an excessive cooling capacity of combined absorption-ejector chiller above current heat loads, generated at the decreased heat loads on the air cooler at the inlet of GTU, can be used for covering the increased heat loads on the air cooler to reduce the cooling capacity of the absorption-ejector chiller installed by about $50 \%$. 


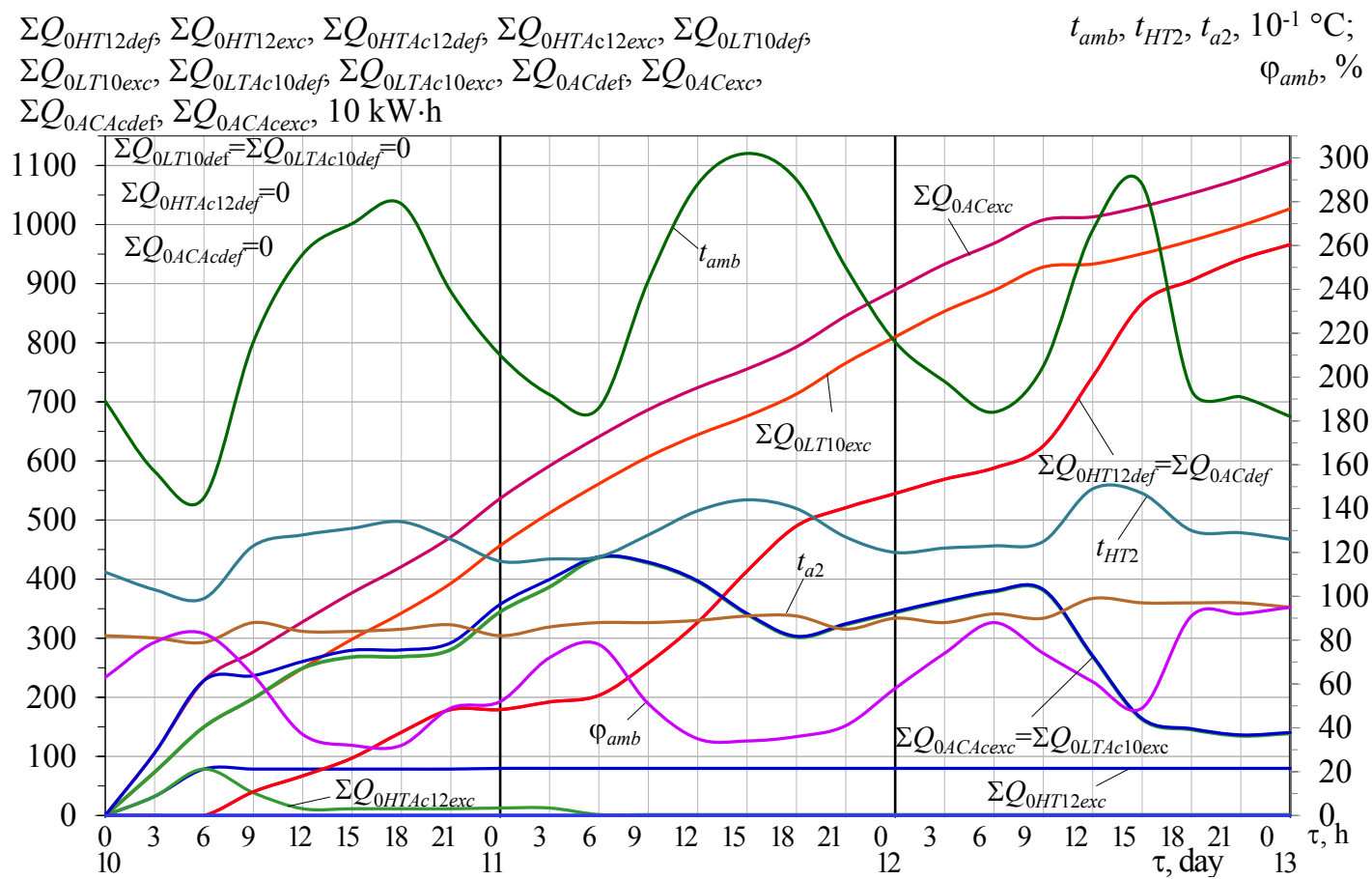

Fig. 4. The current values of the ambient air temperature $t_{a m b}$, after $\mathrm{AC}_{\mathrm{HT}} t_{H T 2}$, after $\mathrm{AC}_{\mathrm{LT}} t_{a 2}$, relative humidity of the ambient air at the inlet $\varphi_{a m b}$, the total deficit $\Sigma Q_{0 H T 12 d e f}$ and the excess $\Sigma Q_{0 H T 12 e x c}$ of the ACh cooling capacity (without using the cooling capacity reserve in the booster stage $\mathrm{AC}_{\mathrm{B}}$ ), the total deficit $\Sigma Q_{0 H T A c 12 \mathrm{def}}$ and the excess $\Sigma Q_{0 H T A c 12 e x c}$ of the cooling capacity of the ACh (with using the cooling capacity reserve in the booster stage $\mathrm{AC}_{\mathrm{B}}$ ), the total deficit $\Sigma Q_{0 L T 10 d e f}$ and the excess $\Sigma Q_{0 L T 10 e x c}$ of the cooling capacity of the $\mathrm{ECh}$ (without using the cooling capacity reserve in the booster stage $\mathrm{AC}_{\mathrm{B}}$ ), a total deficit $\Sigma Q_{0 L T A c 10 d e f}$ and the excess $\Sigma Q_{0 L T A C 10 e x c}$ of the cooling capacity of the ECh (with using the cooling capacity reserve in the booster stage $\mathrm{AC}_{\mathrm{B}}$ ), the total deficit $\Sigma Q_{0 A C d e f}$, and the excess $\Sigma Q_{0 A C e x c}$ of the cooling capacity for two-stage air cooler (without using the cooling capacity reserve in the booster stage $\mathrm{AC}_{\mathrm{B}}$ ), and the total deficit $\Sigma Q_{0 A C A c d e f}$, and the excess $\Sigma Q_{0 A C A c e x c}$ of the cooling capacity for the proposed air cooler (with using the cooling capacity reserve in the booster stage $\mathrm{AC}_{\mathrm{B}}$ ) within 3 days (10-12.07.2017).

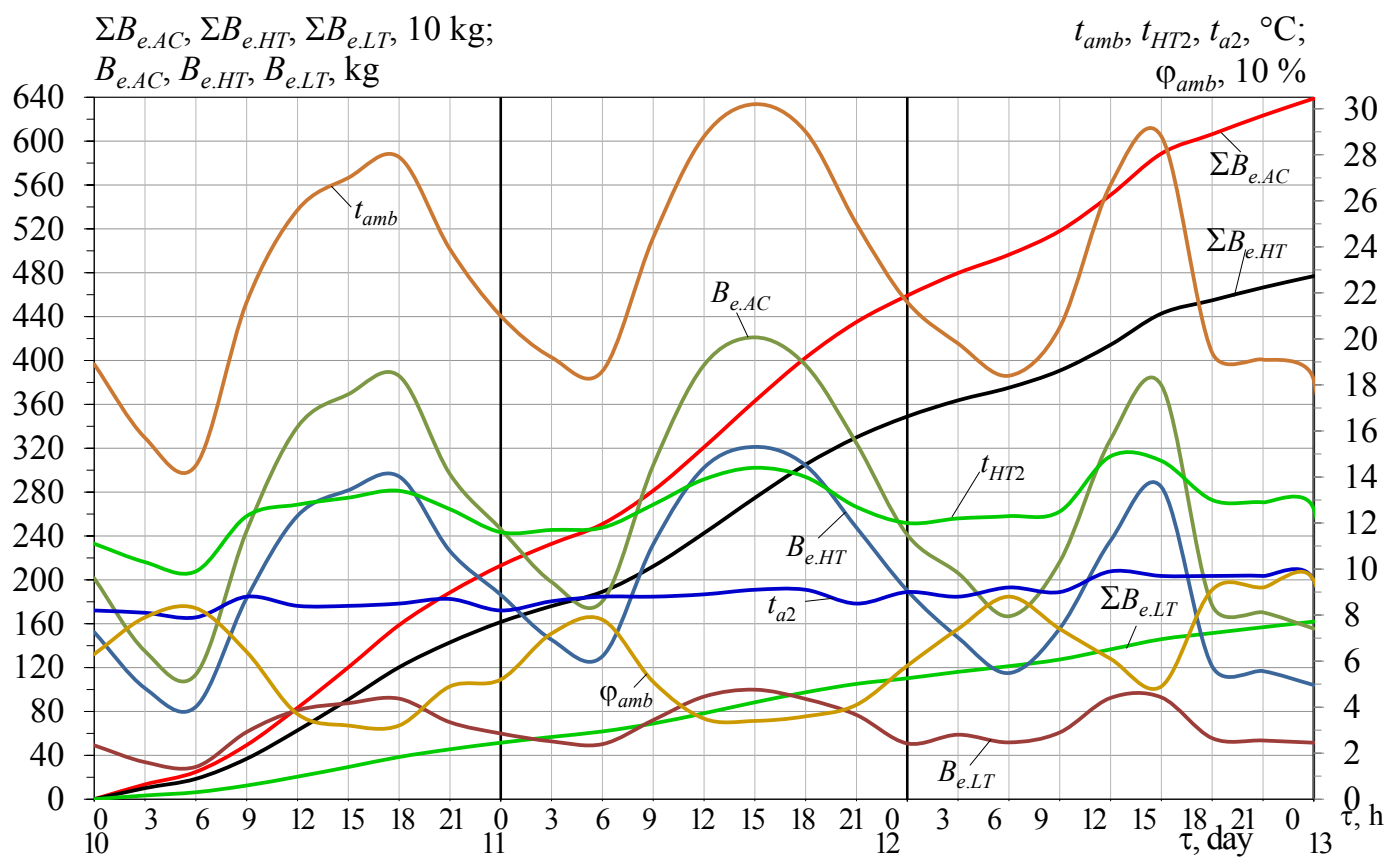

Fig. 5. Current values of the ambient air temperature $t_{a m b}$, the temperature after $\mathrm{AC}_{\mathrm{HT}} t_{H T 2}$, after $\mathrm{AC}_{\mathrm{LT}} t_{a 2}$, relative humidity of the ambient air at the inlet $\varphi_{a m b}$, current fuel saving $B_{e . H T}$ for $\mathrm{AC}_{\mathrm{HT}}, B_{e . L T}$ - for $\mathrm{AC}_{\mathrm{LT}}$ and $B_{e . A C}$ - for the whole $\mathrm{AC}$, the total fuel saving for the high-temperature cooling stage $\Sigma B_{e . H T}, \Sigma B_{e . L T}$ - for low-temperature cooling stage and the total fuel saving $\Sigma B_{e . A C}$ for the whole air cooler. 


\section{Conclusions}

An improved two-stage GTU inlet air cooling to the temperature $15{ }^{\circ} \mathrm{C}$ in the high-temperature stage $\mathrm{AC}_{\mathrm{HT}}$ of air cooler by absorption lithium-bromide chiller (ACh) and to the temperature $10^{\circ} \mathrm{C}$ in the low-temperature stage $\mathrm{AC}_{\mathrm{HT}}$ by refrigerant ejector chiller $(\mathrm{ECh})$ through utilizing the turbine exhaust gas heat has been proposed.

It is shown the possibility of decreasing the project (installed) cooling capacity of the ACh by using the excessive cooling capacity conserved during reduced current heat loads to cover increased heat loads through precooling ambient air in the booster stage $\mathrm{AC}_{\mathrm{B}}$ for twostage air cooler at the inlet of GTU.

For the south Ukraine climatic conditions the application of ambient air precooling booster stage for two-stage air cooler at the GTU inlet provides a reduction of the installed cooling capacity of ACh by about $50 \%$ due to the use of cooling capacity reserve to match the changeable heat loads caused by current climatic conditions.

\section{References}

1. S. Popli, P. Rodgers, V. Eveloy, App. Energy, 93, 623-636 (2012)

2. S. Popli, P. Rodgers, V. Eveloy, App. Thermal Engineering, 50, 918-931 (2013)

3. A. N. Radchenko, N. I. Radchenko, S. A. Kantor, B. S. Portnoi Aerospace technic and technology, 6 (132), 55-59 (2016)

4. A. N. Radchenko, S. A. Kantor, Aerospace technic and technology, 4 (121), 76-79 (2015)

5. A. N. Radchenko, S. A. Kantor, Aerospace technic and technology, 5 (122), 61-64 (2015) 